\title{
HEALTH HAZARDS AMONG FIRE FIGHTERS
}

\author{
By \\ Helal SF* and Labib D**
}

FROM

Industrial Medicine and Occupational Diseases department*, Clinincal Pathology department** Faculty of Medicine-Cairo University

\begin{abstract}
Background: Fire fighting is a physically demanding hazardous occupation. Fires are fought in a dynamic, changing, uncontrolled environment exposing workers to potentially toxic agents. The hazards of firefighting are classified as chemical, biological, physical, psychological and ergonomical. Objective: The aim of the present study was: (1) To investigate some of the health hazards among fire fighters with special emphasis on cytogenetic study and ventilatory functions. (2) To monitor the biological, psychological, reproductive and musculo-skeletal hazards. Subjects and methodology: This study was conducted in a fire fighting station in El Omrania El Sharkia in Giza. The study was accomplished during the month of March 2007. The studied group comprised 24 workers in the fire fighting station. They were adult men aged between 18-33 years ( $23.20 \pm 4.09)$, working on the basis of 12 hours/day with no day off. None of the workers used any protective equipment during working hours. They worked according to the need for help, and not all the time, bearing in mind that the worker may be exposed to frequent shifts or may be not exposed for several days. A referent group of 20 males matched for age [that ranged from 21-35 yrs., (23.40 \pm 4.05) ] , sex, socio-economic status and smoking habit, selected from relatives of the Kasr El Eini hospital patients, were also enrolled in our study. The following investigations were performed after taking individual consent: (A) All workers were interviewed using a special questionnaire including occupational history; and full clinical examination was performed. (B) Ventilatory function tests were evaluated using a portable spirometer connected to a portable computer using the soft ware ZAN program, measuring FVC (Forced vital capacity), SVC (Slow vital capacity), FEV1\%
\end{abstract}


(Forced expiratory volume in the 1st second), FEV1/FVC \%, PEF (Peak expiratory flow) and (Mid expiratory flow 25-75\%) MEF 25-75\%. (C) Serological tests: aHBV: Using enzyme linked immuo-sorbent assay (ELISA) HBsAg using BIORAD Monolisa HBsAg ultra , Lot 7C0029 Monoclonal kit. b-HCV: Anti HCV using 3rd generation enzyme linked immuno sorbent-assay (ELISA) Innotest HCV Abs, Lot 165678. (D) Cytogenetic study Results: showed a statistically significant difference between the exposed and the control groups as regards spirometric evaluation. Our results revealed also a statistically significant difference between the exposed and the control groups as regards the chromosomal study, bearing in mind that the difference was in structural form not the numerical form. There was also a statistically significant difference between both groups as regards the occurrence of accidents, but there was no statistically significant difference between both groups as regards the psychological or reproductive hazards. Our research showed a statistically significant difference between the exposed and the control groups as regards HBV and HCV infections. Our results showed that there was a statistically significant correlation between the duration of exposure to toxins and hazardous agents in fire fighting and ventilatory function parameters. Our work illustrated that there was a statistically significant correlation between duration of exposure to toxins and hazardous agents in fire fighting and the appearance of gap and unbalanced re-arrangement in the chromosomal study, but there was no statistically significant correlation as regards the rest of the chromosomal study. We demonstrated also that there was no statistically significant correlation between the age of the workers and the chromosomal aberrations. Recommendations: From the present study we recommend pre-employment and periodic medical examinations that should be performed to exclude those susceptible to lung diseases. Personal protective clothes and respiratory protective equipment should be used by fire fighters. Health education programs of workers about hazards of exposure to harmful agents and proper measures for protection is essential and this includes training programs to raise awareness among fire fighters. Vaccination program should be applied to cover all the fire fighters specially against (HBV) . Rapid prophylactic treatment to injured workers and reporting system is mandatory. Finally follow recommended shift work pattern.

Key words: Chromosomal aberration-Fire fighting- Health hazards.

\section{Introduction}

The main job of fire fighters is to respond to emergencies in many different kinds of locations with a view to saving life, performing rescue operations and minimizing damage to life. Preparation for responding and prevention are also important aspects of this work. Fire-fighters work under constantly changing and often unstable circumstances. A burning build- 
ing with occupants in need of rescue may lack its normal structural integrity, and means of access such as stairs or lifts may be compromised by the fire. The work is also often strenuous and many situations will require the use of specialized personal protective equipment. Fire-fighters may be called upon to work in different emergency situations such as traffic accidents, industrial disasters, floods, earthquakes, civil riots, hazardous chemical or hazardous materials spills, and aviation or maritime accidents. They may also be called upon to perform rescue in different environments such as rescue from vehicles, rescue from heights and rescue from underground. Fire-fighting is a very high risk occupation. Both occupational injuries and occupational diseases can lead to disability and death ( Matticks et al., 1992). DNA singlestrand breaks and chromosomal aberrations were increased in fire fighters exposed to o-nitroanisole and other substances (Hengstler et al., 1995). Posniak (2000) reported that above 130 chemicals were detected in the environment of the fire attendance. Among them aliphatic hydrocarbons C6-C16 were dominant. Benzene and its aliphatic homologues were also found in all air samples. The carbon monoxide concentration accounted for up to $720 \mathrm{mg} /$ $\mathrm{m} 3$. Concentrations of nitrogen dioxide, sulfur dioxide, formaldehyde and benzene ranged from 0.0 to $49.9 \mathrm{mg} / \mathrm{m} 3 ; 84.5 \mathrm{mg} /$ $\mathrm{m} 3 ; 5.3 \mathrm{mg} / \mathrm{m} 3$ and $89.4 \mathrm{mg} / \mathrm{m} 3$, respectively. The fact that the working environment during emergencies is hostile and unpredictable and that the fire-fighter cannot be prepared for every eventuality requires a growing level of sophistication in training and education and the development of personal protective equipment to protect the fire-fighter from the hazards of the job. According to the International Labor Office (ILO), there have been some studies that have shown some long term health consequences from fire fighting. In other studies, similar connections could not be made. In either case, the need for working safely is extremely important. Guidotti (1998) reported that fire fighters will need to know the risk associated with blood borne diseases e.g: AIDS, HCV and HBV, and they should use the correct universal precautions procedures to prevent blood borne pathogen infection. Fire fighters may experience cancer, especially genitourinary (including kidney, ureter and bladder) but also possibly brain cancer, and cancers of the lymphatic and hematopoietic (blood) system. Back injuries and other strains, diseases such as AIDS and hepatitis are also a hazard. Cardiovascular disease may occur due to a multitude of toxic 
substances when fighting a fire. For example, carbon monoxide exposure is directly linked with cardiac toxicity. Under further study are: Chronic diseases, which are thought to be in part due to the toxic gases produced during a fire. The hazards of fire fighting are classified as chemical, biological, physical, psychological, and ergonomical (Guidotti 1998). On the scene of a fire, there is exposure to various combustion products. The toxicity of the smoke depends greatly on the fuel (the materials or chemicals being burnt), the heat of the fire, and how much oxygen is available for combustion. Common combustion products include: carbon monoxide, hydrogen cyanide, nitrogen dioxide and many others. In addition, oxygen depletion from the air is common during fires. "Hypoxia" (the condition caused by little or no oxygen in the air) can result in impairment of physical performance, confusion and inability to escape Brandt-Rauf (1988).

\section{Aim of the work:}

The aim of the present study was: (1) To investigate some of the health hazards among fire fighters with special emphasis on cytogenetic study and ventilatory functions. (2) To monitor the biological ,psychological, reproductive and musculoskeletal hazards.

\section{Subjects and methods:}

This study was conducted in a fire fighting station in El Omrania El Sharkia in Giza. The study was accomplished during the month of March 2007.

The studied group comprised 24 workers in the fire fighting station. They were adult men aged between 18-33 years (23.20 \pm 4.09$)$, working on the basis of 12 hours/day with no day off. None of the workers used any protective equipment during working hours. They worked according to the need for help, and not all the time bearing in mind that the worker may be exposed to frequent shifts or may be not exposed for several days. A referent group of 20 males matched for age [that ranged from 21-35 yrs., (23.40 \pm 4.05$)$ ], sex, socio-economic status and smoking habit, selected from relatives of the Kasr El Eini hospital patients, were also enrolled in our study. The following investigations were performed after taking individual consent:

(A) All workers were interviewed using a special questionnaire including occupational history ; and full clinical examination was performed.

(B) Ventilatory function tests were done using a portable spirometer connected to a portable computer using the soft 
ware ZAN program, measuring $\mathrm{FVC}$ (Forced vital capacity), SVC (Slow vital capacity), FEV1\% (Forced expiratory volume in the 1st second), FEV1/FVC \%, PEF (Peak expiratory flow) and ( Mid expiratory flow 25-75\%) MEF25-75\%. (C) Serological tests: sera obtained by taking 5 $\mathrm{ml}$ of venous blood from each person in sterilized tubes, which were then centrifuged in clinical pathology department to be tested for HBV and HCV as follow:

a-HBV: Using enzyme linked immuno sorbent assay (ELISA): HbsAg using BIORAD Monolisa HBsAg ultra , Lot 7C0029 Monoclonal kit.

b-HCV: Anti HCV using 3rd generation enzyme linked immuno sorbent assay (ELISA). The third generation enzyme linked immuno sorbent assay (ELISA) Innotest HCV Abs, Lot 165678. It includes antigens from the putative core, NS3, NS4 and NS5 regions of the virus (Courouce et al., 1994). (D) Cytogenetic analysis of lymphocytes using tissue culture and slide preparation from peripheral blood ( Karyotyping) : Lymphocyte cultures were set up using a modification of the techniques of Moorhead and his colleagues (1960) as mentioned below:

a)Blood Sampling:-

From each subject, $5 \mathrm{ml}$ of venous blood were obtained under strict aseptic measures in a heparinized syringe and mixed gently to prevent clotting. Culturing was performed in a sterilized laminar air flow, to avoid contamination of the samples and assure successful cultures.

b) Culture technique:

1-Two culture tubes labeled for each subject. Each tube contained :

-4 ml RPMI 1640 medium.

$-1 \mathrm{ml}$ foetal bovine serum.

-L-Glutamine.

$-0.02 \mathrm{ml}$ Penicillin streptomycin.

$-0.3 \mathrm{ml}$ phytohemagglutinin.

2-0.5 $\mathrm{ml}$ of blood were added to each culture tube then the contents were gently mixed by shaking for a few seconds.

3- The tubes were incubated at $37^{\circ} \mathrm{C}$ for 3 days in a slanting position. This position created more surface area between the liquid and the gaseous phase and allowed the cells to settle over a larger area of the culture tube.

c) Harvesting:

Lymphocytes were harvested on the third day.

1-Colchicine treatment:

- At the end of the incubation, $0.2 \mathrm{ml}$ of colchicine was added to each of the culture tubes while mixing by gentle shaking 
the cultures, then they were incubated at $37^{\circ} \mathrm{C}$ for 30 minutes.

-The addition of colchicine arrests cells division at the metaphase stage when the chromosomes are most suitable for study.

-The culture tubes were centrifuged at $1000 \mathrm{rpm}$ for $10-15$ minutes.

-The supernatant was discarded using Pasteur pipette, leaving as little medium as possible over the cell button (Pellet). The cells were then resuspended by gentle shaking.

2-Hypotonic treatment:

$-5 \mathrm{ml}$ of hypotonic KCL solution (0.04) were added drop by drop to the side of the tube while shaking gently. The hypotonic solution was pre-warmed to $37^{\circ} \mathrm{C}$ before use.

-The use of hypotonic solution causes the cells to swell, disperses the chromosomes and makes them easier to identify and count.

The cell suspension was incubated at $37^{\circ} \mathrm{C}$ for 30 minutes.

-The tubes were rotated in the centrifuge for 10 minutes.

-The supernatant was discarded.

3-Fixation:
$-5 \mathrm{ml}$ of freshly prepared fixative (1 part glacial acetic acid+ 3 parts absolute methyl alcohol) were added drop by drop to the side of the tube, while mixing gently for few minutes. The addition of fixative helps fixation of the cells.

-The tubes were left in the refrigerator for at least 1 hour.

-The tubes were rotated in the centrifuge for 10-15 minutes.

-The supernatant was discarded.

-The steps were repeated 4 times.

-After the final centrifugation the cells were suspended in $0.05 \mathrm{ml}$ of fixative.

d)Slide preparation:-

1-Using a Pasteur pipette, 2 to 3 drops of the cell suspension were allowed to fall from a height of $20-30 \mathrm{~cm}$ on a 45 tilted cold slide. This procedure aimed at rupturing the swollen cells and spreading the chromosomes.

2-The slides were blown gently to help spreading the drops.

3-The slides were left to dry on the hot plate at $40^{\circ} \mathrm{C}$ for $30-45$ seconds.

e) Staining:

1-Preparation of Giemsa stock solution:-

$-1 \mathrm{gm}$ of Giemsa powder was added to 
$66 \mathrm{ml}$ glycerol and left for 1.5-2 hours in a water path at $60^{\circ} \mathrm{C}$ with continous shaking.

-After it cooled down, $66 \mathrm{ml}$ of methyl alcohol were added. Then the mixure was filtered and stored in a dark bottle for at least one week before use.

\section{2-Slides staining (Giemsa staining):}

-Preparation of $4 \%$ Giemsa solution: To each $1 \mathrm{ml}$ of Giemsa stock solution, 1 $\mathrm{ml}$ of phosphate buffer (pH 6.8) and $23 \mathrm{ml}$ distilled water were added to obtain the 4\% Giemsa solution.

-Staining: The Giemsa solution 4\% was put in a coplin jar 2-3 slides from each tube were left in the stain for 5 minutes. The slides were then washed in tap water and left to dry, in the vertical position, before examination.

-Examination: For various structural and numerical aberrations, using the low power objective, the slides were screened for well spread metaphases. If the culture was found to be successful with a satisfactory mitotic index, 30 metaphases were scored for chromosomes.

Strict aseptic measures were followed while withdrawing the blood samples and setting up the cultures which should be performed inside a thoroughly sterilized laminar air flow and sterile gloves were used in order to avoid infection in the cultures of the study.

Abnormal structural chromosomal study were in the form of: Chromatid gap: It is a chromatid discontinuity, the width of which is less than the chromatid width (Connor and Ferguson-Smith 1984). Chromatid break: It occurs when there is a complete separation of the two segments of a chromatid leaving a distance between the two fragments greater than the width of the same chromatid (Connor and Ferguson-Smith 1984). If the gap or break involves both chromatides of a chromosome the lesion is named an iso-gap (chromosome gap) or an iso-break (chromosome break) respectively (Borganokar, 1989). Deletion: It is the loss of chromosome segment. It may be terminal or interstitial (Borganokar, 1989). Unbalanced rearrangement: The phenotype in this type of rearrangement is likely to be abnormal because of deletion, duplication or both (Thompson et al., 1991). Balanced rearrangements: These rearrangements do not usually have a phenotypic effect because all the genetic information is present even it is packaged differently, but their carriers are likely to produce a high frequency of unbalanced offsprings (Borganokar, 1989). 


\section{Results and discussion:}

Firefighters are exposed to chemicals through combustion and pyrolysis products during the fire and after it is extinguished. The major chemical hazards of combustion include those displacing oxygen such as carbon monoxide that interferes with oxygen transport, delivery cyanide, soot contains carcinogens as benzopyrene and polyaromatic hydrocarbons and irritants as aldehydes (acrolein and formaldehyde). Elevated levels of these substances lead to acute changes in air way reactivity as shown in our work in (table 1) as there was a statistically significant difference between the exposed and the control groups as regards all ventilatory function parameters. Our findings were in accordance with findings obtained by (Kales et al., 1997) who demonstrated that exposure to combustion products and respiratory irritants in firefighting lead to impairment of the ventilatory functions of the workers and they reported also that acute exposure causes reversible changes and airway responsiveness while chronic exposure as in our work cause decrease in all the parameters of ventilatory functions .

Table (1): Comparison between the exposed and control groups as regards different ven-

tilatory function parameters:

\begin{tabular}{|c|c|c|c|c|c|c|}
\hline \multirow[b]{2}{*}{ Investigations } & \multicolumn{2}{|c|}{$\begin{array}{l}\text { Exposed group } \\
\mathrm{N}: 24\end{array}$} & \multicolumn{2}{|c|}{$\begin{array}{l}\text { Control group } \\
\qquad \mathrm{N}: 20\end{array}$} & \multirow{2}{*}{$\mathrm{t}$ test } & \multirow[t]{2}{*}{$P$ value } \\
\hline & Mean & $\pm \mathrm{SD}$ & Mean & $\pm \mathrm{SD}$ & & \\
\hline $\mathrm{FVC} \%$ of the predicted & 77.20 & \pm 6.75 & 86.10 & \pm 4.3 & 5.07 & $<0.001$ \\
\hline SVC\% of the predicted & 80.20 & \pm 6.74 & 89.75 & \pm 3.8 & 5.6 & $<0.001$ \\
\hline FEV $1 \%$ of the predicted & 76.91 & \pm 6.5 & 87.40 & \pm 3.67 & 6.3 & $<0.001$ \\
\hline FEV1/FVC & 74.16 & \pm 7.4 & 82.75 & \pm 2.3 & 4.9 & $<0.001$ \\
\hline PEF\% of the predicted & 69.62 & \pm 7.9 & 80.20 & \pm 3.1 & 5.5 & $<0.001$ \\
\hline $\begin{array}{l}\text { MEF } 25 / 75 \% \text { of the pre- } \\
\text { dicted }\end{array}$ & 61.1 & \pm 8.3 & 75.5 & \pm 4.6 & 6.6 & $<0.001$ \\
\hline
\end{tabular}


In our work, the effect of smoking could not be studied because there was no statistically significant difference between both groups as regards smoking habit as shown in (table 2).

Firefighters require the ability to perform at peak physical levels under very dangerous conditions not amenable to usual controls available in other work locations. We found in our study that there was a statistically significant difference between the exposed and the control groups as regards the occurrence of accident in the form of broken limbs or burn during work as shown in ( table 3). Matticks and his colleagues (1992) showed in their work that firefighters work in varied and dangerous circumstances and face unique health hazards that expose them to specific physical injuries, disability and even death, and these results were in agreement with our work. Death results from fire or unusual traumatic incidents as explosions. These cause psychological stress reactions manifested by anxiety, depression, fear and phobia requiring rapid intervention as mentioned by Guidotti (1998) . These findings were not supported by our results as shown in (table 3 ) as none of the examined workers in our research complained from any psychological troubles. This may be explained by the fact that Egyptians like to help in any hazardous situations and they find a marvelous opportunity to help those who need help which gives them pride. In our research there were only 3 married workers among the firefighters and 7 married persons in the control groups, all of them had no reproductive problems and all of them had normal children as shown in (table 3). Contrary to our findings McDiarmid and his co-workers (1991) were con-

Table (2): Smoking habit among the examined groups:

\begin{tabular}{|c|c|c|c|c|c|}
\hline \multirow{2}{*}{$\begin{array}{c}\text { Studied } \\
\text { group }\end{array}$} & \multicolumn{2}{|c|}{ Smokers } & \multicolumn{2}{c|}{ Non smokers } & \multirow{2}{*}{ Total } \\
\cline { 2 - 5 } & $\mathrm{N}$ & $\%$ & $\mathrm{~N}$ & $\%$ & \\
\hline Exposed & 6 & 25 & 18 & 75 & 24 \\
\hline Control & 5 & 20 & 15 & 80 & 20 \\
\hline Total & 11 & & 33 & & 44 \\
\hline $\mathrm{X} 2$ & 0.00 & & & \\
\hline P value & $>0.05$ &
\end{tabular}


cerned in their work with reproductive toxicity in firefighters who were exposed to heat that could affect the motility and the count of the sperms and they were also exposed to agents in fire smoke as diesel exhaust particles, polycyclicaromatic hydrocarbons and perchloroethylene and they proved the presence of reproductive toxicity in firefighters. Our findings could be explained by the fact that there was a small number of married workers who were asked about their reproductive abnormalities and this was also due to the fact that firefighters examined in our work were young aged and the duration of exposure to these hazards was short.

The risk of exposure to biological hazards among firefighters as, (HBV) $\&(\mathrm{HCV})$ is high, as they are exposed to blood and body fluids . Our study revealed a statistically significant difference between the exposed and the control groups as regards the prevalence of $(\mathrm{HBV}) \&(\mathrm{HCV})$ as shown in (table 4). Spitters and his colleagues (1995) reported that, first responders (e.g., firefighters, emergency medical technicians, and paramedics) were at risk for occupational exposure to blood borne pathogens such as AIDS, hepatitis B and C viruses while helping victims of fire or accidents and they had high risk to acquire these infections. This is in accordance with our results. Guidotti (1998) was also in agreement with our results as he reported increased risk of acquiring $\mathrm{HBV}, \mathrm{HCV} \&$ HIV infections among firefighters.

Table(3): The prevalence of occurrence of accident, psychological troubles and reproductive problems during work:

\begin{tabular}{|c|c|c|c|c|c|c|}
\hline \multirow{2}{*}{ Accident } & \multicolumn{2}{|c|}{$\begin{array}{c}\text { Exposed group } \\
\qquad \mathrm{N}: 24\end{array}$} & \multicolumn{2}{|c|}{$\begin{array}{c}\text { Control group } \\
\mathrm{N}: 20\end{array}$} & \multirow[t]{2}{*}{$\mathrm{X} 2$} & \multirow[t]{2}{*}{$\mathrm{P}$ value } \\
\hline & $\mathrm{N}$ & $\%$ & $\mathrm{~N}$ & $\%$ & & \\
\hline Broken limb & 6 & 25 & 0 & 0 & 5.7 & $<0.05$ \\
\hline Burn & 3 & 12.5 & 0 & 0 & 2.6 & $<0.05$ \\
\hline Psychological troubles & 0 & 0 & 0 & 0 & & \\
\hline Reproductive problems & $0 / 3$ married & 0 & $0 / 7$ married & 0 & & \\
\hline
\end{tabular}


Table (4): The prevalence of Hepatitis B virus (HBV) and hepatitis C virus (HCV) infections among the examined group:

\begin{tabular}{|c|c|c|c|c|c|c|}
\hline \multirow[b]{2}{*}{ Investigations } & \multicolumn{2}{|c|}{$\begin{array}{l}\text { Exposed group } \\
\qquad \mathrm{N}: 24\end{array}$} & \multicolumn{2}{|c|}{$\begin{array}{c}\text { Control group } \\
\text { N:20 }\end{array}$} & \multirow[t]{2}{*}{$\mathrm{X} 2$} & \multirow[t]{2}{*}{$P$ value } \\
\hline & $\mathrm{N}$ & $\%$ & $\mathrm{~N}$ & $\%$ & & \\
\hline HBsAg & 7 & 29.16 & 1 & 5 & 4.28 & $<0.05$ \\
\hline HCV antibodies & 7 & 29.16 & 1 & 5 & 4.28 & $<0.05$ \\
\hline
\end{tabular}

Jacobson and his co-workers (1993) had found various indicators of DNA damage in peripheral lymphocytes of human populations potentially at increased risk for cancer. They reported sister chromatid exchanges (SCE) ; chromosomal aberrations and gene mutations and polycyclic aromatic hydrocarbon (PAH)-DNA adducts in a group of firefighters. Our findings were also in relative resemblance to the above findings as we found a statistically significant difference between the exposed and the control groups as regards the chromosomal aberrations, but not with the rearrangement which showed no statistically significant difference between both groups as shown in ( table 5). Lazutka and Rimdeika (2006) were in accordance with our results as they demonstrated in their work that the frequency of sister chromatid exchanges (SCEs), chromosomal breaks, iso breaks, gaps, iso gaps, centromere separation and total frequency of chromoso- mal aberrations among firefighters and clean up workers after Chernobyl disaster were significantly higher than that of controls. To monitor the genetic aftereffects of the disaster, sister chromatid changes (SCEs) and chromosomal study of peripheral blood lymphocytes were measured in fire fighters and clean up workers involved in the disaster 8 years after the event. They found that the frequency of SCEs and chromosomal aberrations were still significantly higher in the exposed subjects than the controls, suggesting a risk of the genetic aftereffects of the toxins exposure. In a group of firefighters the level of PAHDNA adducts measured by ELISA in white blood cells was not significantly related to cytochrome P450 1A1 (CYP1A1) genotype. However there was a statistically significant difference between them and the control group as regards the adduct formation and chromosomal aberrations (Rothman et al., 1995). 
Table (5): Chromosomal study among the examined group:

\begin{tabular}{|c|c|c|c|c|c|c|}
\hline \multirow{2}{*}{$\begin{array}{c}\text { Examined } \\
\text { Investigations }\end{array}$} & \multicolumn{2}{|c|}{$\begin{array}{c}\text { Exposed group } \\
\mathrm{N}: 24\end{array}$} & \multicolumn{2}{c|}{$\begin{array}{c}\text { Control group } \\
\mathrm{N}: 20\end{array}$} & \multirow{2}{*}{$\mathrm{t}$ test } & \multirow{2}{*}{ P value } \\
\cline { 2 - 5 } & Mean & $\pm \mathrm{SD}$ & Mean & $\pm \mathrm{SD}$ & & \\
\hline Gap & 8.29 & \pm 1.68 & 1.05 & \pm 0.82 & 17.5 & $<0.001$ \\
\hline Isogap & 4.20 & \pm 0.93 & 0.90 & \pm 0.64 & 13.44 & $<0.001$ \\
\hline Break & 1.91 & \pm 0.71 & 0.65 & \pm 0.48 & 6.69 & $<0.001$ \\
\hline Isobreak & 1.95 & \pm 0.62 & 0.50 & \pm 0.60 & 7.81 & $<0.001$ \\
\hline Centromere separation & 1.6 & \pm 0.88 & 0.80 & \pm 0.67 & 3.05 & $<0.001$ \\
\hline Deletion & 1.75 & \pm 1.07 & 0.75 & \pm 0.71 & 3.55 & $<0.001$ \\
\hline Unbalanced re- & 0.20 & \pm 0.50 & 0.00 & \pm 0.00 & 1.82 & $>0.05$ \\
arrangement & & & & & & \\
\hline Total aberrations & 19.91 & \pm 3.3 & 4.7 & \pm 2.8 & 17.9 & $<0.001$ \\
\hline
\end{tabular}

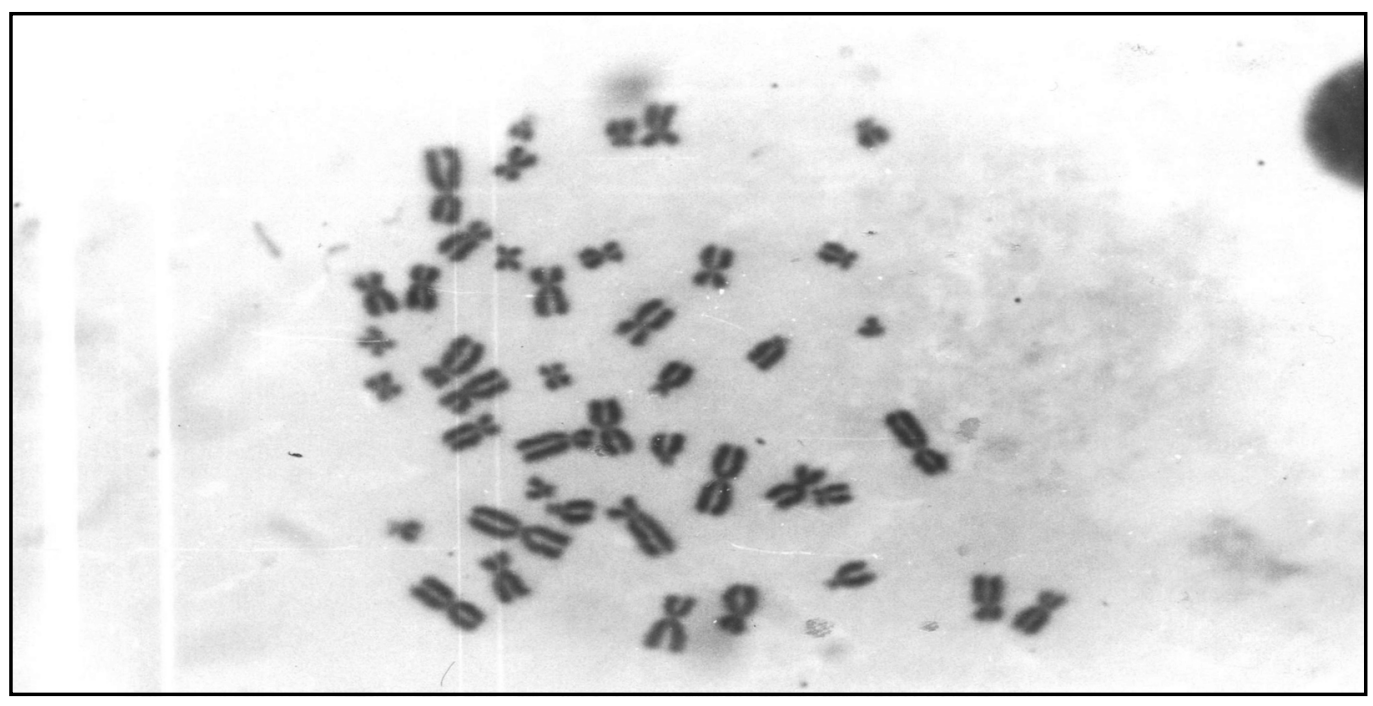

Fig (1): Normal chromosomal study, No structural aberrations 


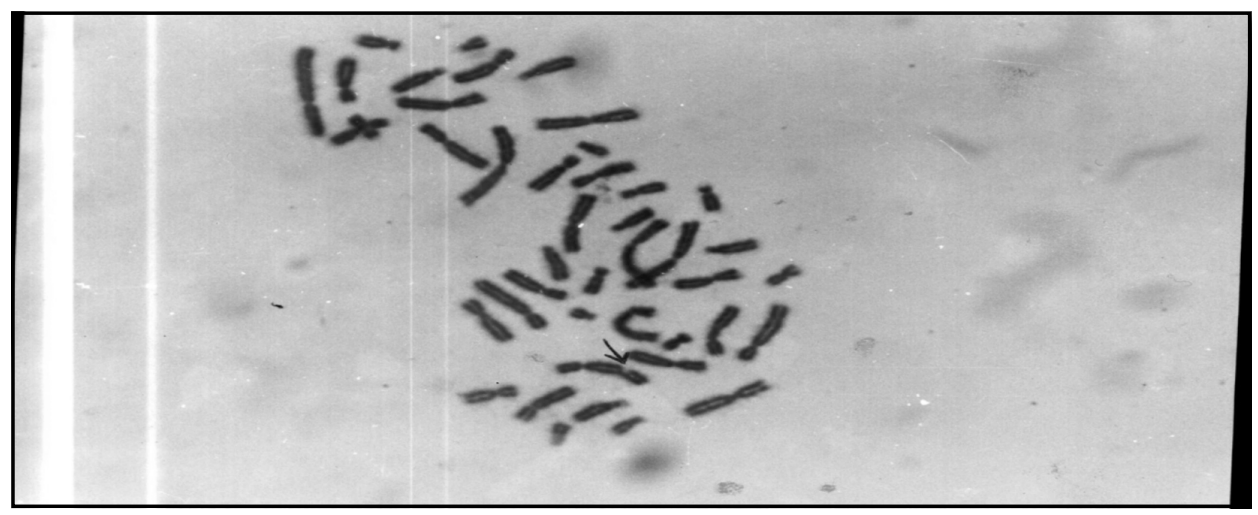

Fig (2): Chromosomal study shows break

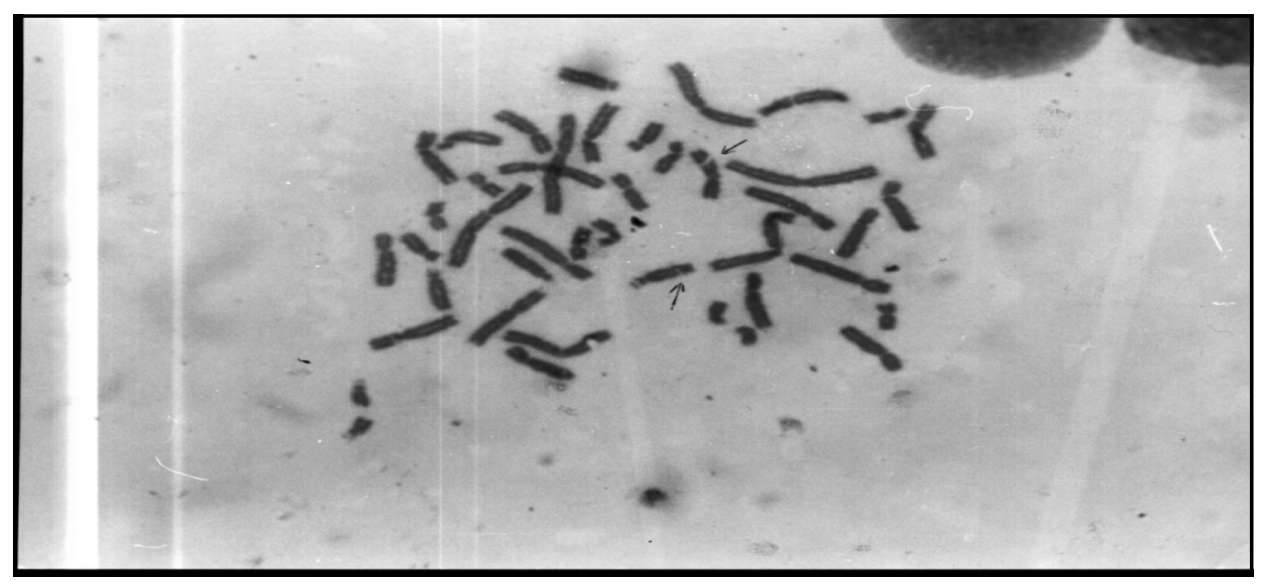

Fig (3): Chromosomal study shows iso-break

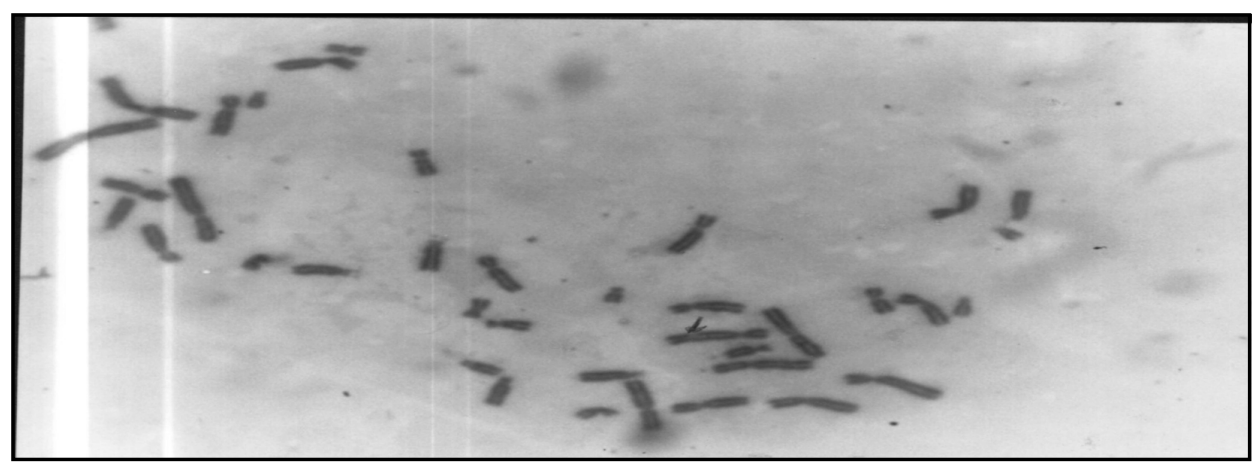

Fig (4): Chromosomal study shows gap 


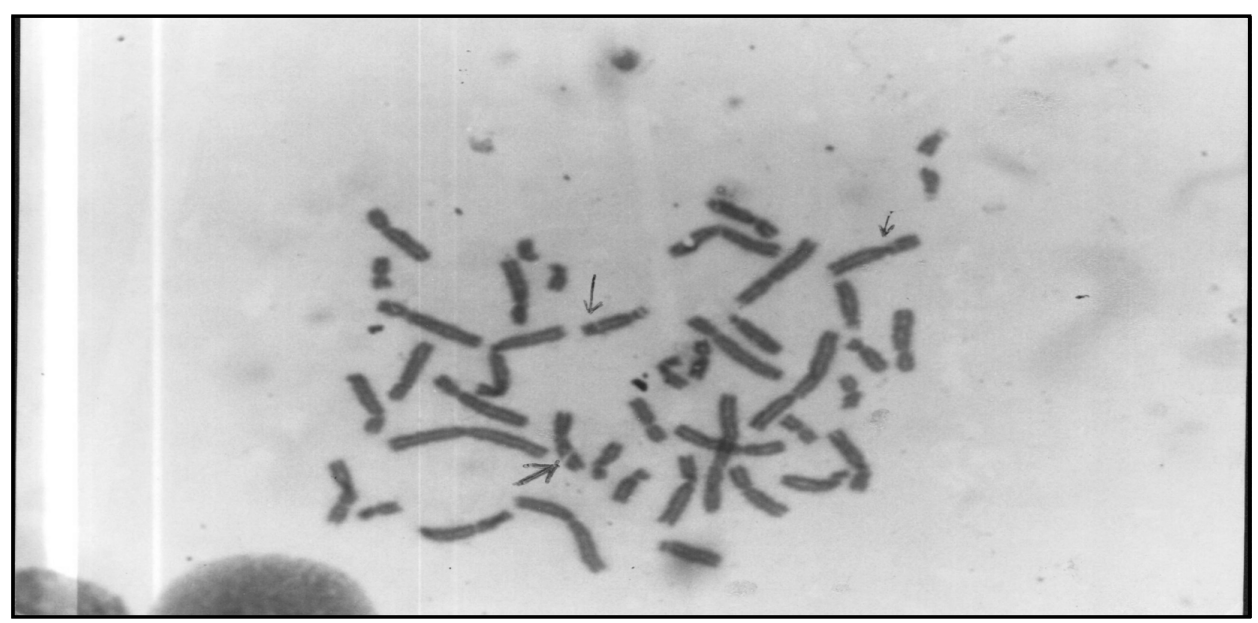

Fig (5): Chromosomal study shows iso-gap

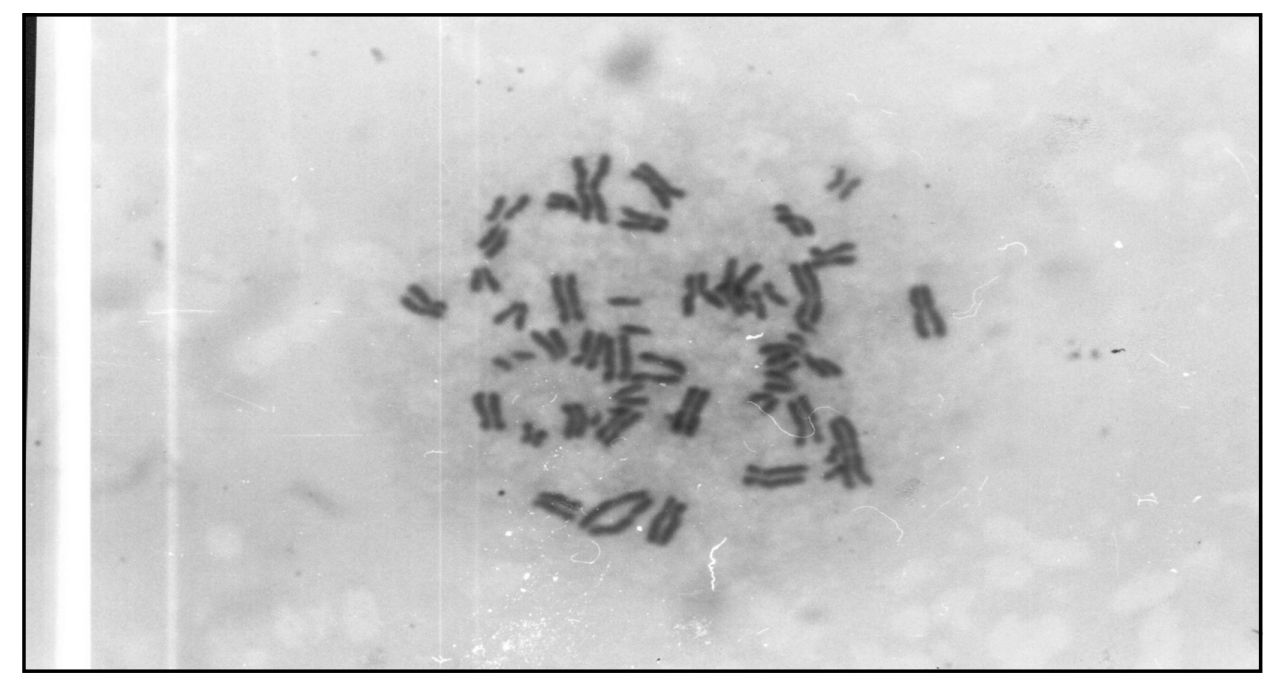

Fig (6): Chromosomal study shows centromere separation 
Table (6): Correlation coefficient between duration of exposure to toxins among fire fighters and ventilatory function parameters:

\begin{tabular}{|c|c|c|c|}
\hline Parameters & $\mathrm{r}$ & $\mathrm{F}$ & P value \\
\hline FVC\% & -0.608 & 0.002 & $<0.05$ \\
\hline SVC\% & -0.603 & 0.002 & $<0.05$ \\
\hline FEV1\% & -0.655 & 0.001 & $<0.05$ \\
\hline FEV1/FVC & -0.671 & 0.000 & $<0.001$ \\
\hline PEF\% & -0.642 & 0.001 & $<0.05$ \\
\hline MEF 25-75\% & -0.764 & 0.000 & $<0.001$ \\
\hline
\end{tabular}

In (table 6), we demonstrated that there was a statistically significant negative correlation between the duration of exposure to toxins among fire fighters and all ventilatory function parameters. In accordance with our results Kales and his co-workers (1997) found that exposure to combustion products and respiratory irritants in firefighting lead to impairment of the ventilatory functions of the workers and they reported also that acute exposure causes reversible changes and airway hyper-responsiveness while chronic exposure as in our work, caused decrease in all the parameters of ventilatory functions, and in the workers who were not affected there was decrease in methacholine provocation dose with $35 \%$ decrease in conductance. In agreement with our findings, Andersson and his colleagues (2006) reported that, with chronic exposure to irritant gases such as $\mathrm{SO} 2$ there was an increased incidence of asthma during work in sulpher pulp mills and this increased with the duration of exposure to irritants, which supports the hypothesis of irritant induced asthma.

We found in our work that there was a statistically significant positive correlation between the duration of exposure to toxins among firefighters and the total aberrations, gap, isogap and unbalanced rearrangement as shown in (table 7). Our results were resemblance to the results ob- 
Table (7): Correlation coefficient between duration of exposure to toxins among fire fighters and chromosomal aberrations:

\begin{tabular}{|l|c|c|c|}
\hline \multicolumn{1}{|c|}{ Parameters } & $\mathrm{r}$ & $\mathrm{F}$ & P value \\
\hline Gap & 0.601 & 0.002 & $<0.05$ \\
\hline Isogap & 0.485 & 0.01 & $<0.05$ \\
\hline Break & 0.216 & 0.31 & $>0.05$ \\
\hline Isobreak & 0.23 & 0.26 & $>0.05$ \\
\hline Central separation & 0.192 & 0.63 & $>0.05$ \\
\hline Deletion & -0.205 & 0.33 & $>0.05$ \\
\hline Unbalanced re-arrangement & 0.42 & 0.04 & $<0.05$ \\
\hline Total aberrations & 0.559 & 0.005 & $<0.05$ \\
\hline
\end{tabular}

tained by ( Liou et al., 1989) who reported that firefighters were exposed to potentially carcinogenic combustion and pyrolysis products during the course of their work. This study was designed to test 43 fire fighters and matched controls for DNA damage which have been related to occupational carcinogens, and they found that sensitivity of individual fire fighters to mitomycin C-induced SCE was correlated with the number of fires fought in the previous $24 \mathrm{~h}$.

In this work we found a statistically non-significant correlation between the age of the exposed workers and the chromosomal aberrations as shown in (table 8). Other research done by Greenstock (1993) was against our findings as he reported that all types of radiation and other external stresses interact with nucleic acids, proteins and membrane phospholipids facilitating free radical mediated oxidative damage and these events were associated with increased age and with chronic diseases. The difference between our results and Greenstock's findings may be related to the fact that the exposed workers in our research were aged from 18-33 years, 7 workers were 25 years old or above and 17 workers were below 25 years old, and the number examined was small. Lezhava and Jokhadze (2007) studied the functional characteristics of chromosomes (level of total heterochromatin, chromosome insta- 
Table (8): Correlation coefficient between the age of fire fighters and chromosomal aberrations:

\begin{tabular}{|l|c|c|c|}
\hline \multicolumn{1}{|c|}{ Parameters } & $\mathrm{r}$ & $\mathrm{F}$ & P value \\
\hline Gap & 0.095 & 0.54 & $>0.05$ \\
\hline Isogap & 0.087 & 0.57 & $>0.05$ \\
\hline Break & 0.06 & 0.65 & $>0.05$ \\
\hline Isobreak & 0.092 & 0.55 & $>0.05$ \\
\hline Central separation & 0.32 & 0.83 & $>0.05$ \\
\hline Deletion & -0.131 & 0.39 & $>0.05$ \\
\hline Re-arrangement & 0.21 & 0.46 & $>0.05$ \\
\hline Total aberrations & 0.08 & 0.60 & $>0.05$ \\
\hline
\end{tabular}

bility, and sister chromatid exchanges [SCEs]) in cultured lymphocytes derived from 80 to 91 -year-old and 18 to 30 -yearold (control group). The results obtained showed that chromosomal abnormalities had progressively increased in the aging group in relation to the control group.

\section{Recommendations:}

From the present study we recommend pre-employment and periodic medical examinations that should be performed to exclude those susceptible to lung diseases. Personal protective clothes and respiratory protective equipment should be used by fire fighters. Health education programs of workers about hazards of exposure to harmful agents and proper measures for protection is essential and this includes training programs to raise awareness among fire fighters. Vaccination program should be applied to cover all the fire fighters specially against (HBV) . Rapid prophylactic treatment to injured workers and reporting system is mandatory. Finally follow recommended shift work pattern.

\section{References:}

Andersson E, Knutsson A, Hagberg S, Nilsson T, Karlsson B, Alfredsson L and Toren K (2006): Incidence of asthma among workers exposed to sulphur dioxide and other irritant gases. Eur Respir J.;27(4):720-5. 
Borganokar DS (1989): Chromosomal variation in man. A catalogue of chromosomal variants and anomalies 5th ed. Alan R. Press, New York, p: 73.

Brandt-Rauf PW, Fallon LF , Tarantini T, Idema C and Andrews L(1988): Health hazards of fire fighters: exposure assessment. Br. J. Ind. Med. , 45(9):606-12.

Connor JM and Ferguson-Smith MA (1984): Physical basis of heredity, chromosomes and chromosome aberrations. In: Essen. Med. Genetics, 1st ed, Blackwell Scientific Puplications, London, p:51.

Couroucé AM, Bouchardeau F and Girault A (1994): Significance of NS3 and NS5 antigens in screening for HCV antibody. Lancet 343: 853.

Greenstock CL (1993): Radiation and aging : free radical damage, biological response and possible antioxidant intervention. Med. Hypotheses ; 41 (5): 473-82.

Guidotti T (1998): Firefighting Hazards, in Stellman, J. (Ed) The ILO Encyclopaedia of Occupational Health and Safety, 4th Edition, ILO Geneva, 1998. Vol 3. pp 95.4-9.

Hengstler JG, Fuchs J, Bolm-Audorff U, Meyer S and Oesch F (1995): Single-strand breaks in deoxyribonucleic acid in fire fighters accidentally exposed to o-nitroanisole and other chemicals. Scand J Work Environ Health.;21(1):36-42.
Jacobson-Kram D, Albertini RJ and Branda RF (1993): Measurement of chromosomal aberrations , sister chromatid exchange, hprt mutation, and DNA adducts in peripheral lymphocytes of human populations at increased risk of cancer.

Environmental Health Perspectives ; 101 (3) : 121125. International Conference on Environmental Mutagenesis in Human Populations at risk, Cairo (Egypt).

Kales SN, Polyhronopoulos GN, and Christiani DC (1997): Medical surveillance of hazardous materials response in fire fighters: a two-year prospective study. J Occup Environ Med.;39 (12):1135-6.

Lazutka J R and Rimdeika G J (2006): Frequency of chromosomal damage and health status of Lithuanian clean-up workers. BIOLOGLIA; 1:36-40.

Lezhava $\mathrm{T}$ and Jokhadze $\mathrm{T}$ (2007): Activation of pericentromeric and telomeric heterochromatin in cultured lymphocytes from old individuals. Ann NY Acad. Sci; 1100; 387-99.

Liou SH, Jacobson-Kram D, Poirier MC, Nguyen D, Strickland PT and Tockman MS (1989): Biological monitoring of fire fighters: sister chromatid exchange and polycyclic aromatic hydrocarbonDNA adducts in peripheral blood cells. Cancer Res.; 49 (17):4929-35.

Matticks CA, Westwater JJ, Himel HN, Morgan RF and Edlich RF (1992): Health risks to fire fighters. J Burn Care Rehabil. ;13(2 Pt 1):223-35. 
McDiarmid MA, Lees PS, Agnew J, Midzenski M and Duffy R (1991): Reproductive hazards of fire fighting. II. Chemical hazards. Am J Ind Med. ,19(4):447-72.

Moorhead PS, Nowell PC, Mitelman WJ, Battips DM and Hungerford DA (1960): Chromosome preparation of leukocytes cultured from human peripheral blood. Exp. Cell Res.,20:613.

Posniak M (2000): Chemical hazards in fire-fighting environments. Med Pr.;51(4):335-44.

Rothman N, Shields PG, Poirier MC, Harrington AM, Ford DP and Strickland PT (1995): The impact of glutathione S-transferase M1 and cy- tochrome P450 1A1 genotypes on white-bloodcell polycyclic aromatic hydrocarbon-DNA adduct levels in humans. Mol Carcinogen 14:6368 .

Spitters C, Zenilman J, Yeargain $\mathrm{J}$ and Pardoe $\mathrm{K}$ (1995): Prevalence of antibodies to hepatitis B and $\mathrm{C}$ among fire department personnel prior to implementation of a hepatitis B vaccination program. J Occup Environ. Med ;37:663.

Thompson MW, Mclinnes RR and Willard HF (1991): Genetics . In: Medicine, 5th ed, WB Saunders company, Philadelphia, London, Toronto Tokyo, Sydney, p:22. 